\title{
Electronic Implementation of a Fuzzy Neuron Model With a Gupta Integrator
}

\author{
A. Ramírez-Mendoza*1, J.L. Pérez-Silva² ${ }^{2}$ F. Lara-Rosano ${ }^{3}$ \\ ${ }^{1}$ Posgrado en Ingeniería \\ Universidad Nacional Autónoma de México \\ *ARamirezM@iingen.unam.mx \\ ${ }^{2,3}$ Centro de Ciencias Aplicadas y Desarrollo Tecnológico \\ Universidad Nacional Autónoma de México
}

\begin{abstract}
In this paper the electronic circuit implementation of a fuzzy neuron model with a fuzzy Gupta integrator is presented. This neuron model simulates the performance and the fuzzy response of a fast-spiking biological neuron. The fuzzy neuron response is analyzed for two classical (non-fuzzy) input signals, the results are spike trains with relative and absolute refractory period and an axonal delay. A comparison between the response of the proposed fuzzy neuron model and the intracellular registers of biological fast-spiking cortical interneurons is made, as well as the transients presented at the beginning of each spike train. Also the results obtained from the electronic circuit of the fuzzy neuron model with the Matlab ${ }^{\mathrm{TM}}$ simulation of the mathematical model are compared.
\end{abstract}

Keywords: Artificial neurons, electronic models of neurons, axonal delay, refractory period, fast spiking neuron response, biological based neuron models, interneurons.

\section{RESUMEN}

En este trabajo realizamos la implantación del circuito electrónico del modelo de una neurona con un integrador difuso tipo Gupta que simula el funcionamiento y obtiene una respuesta difusa de una neurona de espigueo rápido; se dan las ecuaciones del modelo de neurona difusa y se obtiene una respuesta difusa de la neurona para dos señales de entrada no difusas. El resultado son trenes de espigas en donde se pueden apreciar el periodo refractario relativo y absoluto, así como el retardo axónico. Se compara la respuesta del modelo de neurona difusa propuesto con registros intracelulares de interneuronas corticales de espigueo rápido biológicas, así como del transitorio que presentan al inicio de cada tren de espigas. También se comparan los resultados obtenidos del circuito electrónico del modelo de neurona difusa con la simulación del modelo matemático de la neurona difusa en Matlab ${ }^{\mathrm{TM}}$.

\section{Introduction}

In the development of artificial neurons, two main research tendencies can be distinguished: one of them is based on the classical logic and the other on the fuzzy logic. The first is characterized by binary truth values and classical logical operations used to describe neuronal processes in the classical artificial neurons [1] [2] [3] [4] [5]. On the other hand, the fuzzy logic developed in the last few decades has been another alternative for the modeling of artificial fuzzy neurons [6] [7] [8] [9]. Instead of binary truth values, they use a truth membership function and fuzzy logic operations for modeling neural processes producing a fuzzy response.

In order to study the electrical properties, to analyze the electrophysiological signals and the electrical behavior of the motor cortical neurons like the fast spiking neurons, several neuron models and circuits [10] [11] [12] [13] [14] [15] [16] [17] have been developed. Some of them have been proposed in order to characterize the most important biological neuron properties like the synaptic operation, the somatic aggregation operation, the non-linear threshold operation, the spike generation, the relative refractory period, the absolute refractory period and the axonal delay. In this way, the biological inspired neuron models are called neuromimes and are an important way to emulate and analyze the time characteristics of the neuron response [18], [19], [20]. 
The fuzzy artificial neuron presented in this paper allows modeling processes like the refractory period, the axonal delay and the spikes generation [21] [22] [23] as well as the fast spiking neurons performance and analyzing the fuzzy neuron model response for different input signals instead of having to do it directly with a biological neuron, taking advantage of the simplicity of the digital processes.

\section{Fuzzy neuron model}

According to Gupta [9], the basic neuron operations are a synaptic operation, an aggregation somatic operation and a non-linear somatic operation with threshold. If these operations are fuzzy then we have a fuzzy neuron. The fuzzy neuron model developed in this paper is biologically inspired in the typical fast spiking neuron response specifically in the cortical interneurons fast spiking response. In order to emulate the neuronal response we propose to consider the synaptic weights with a unit value, the aggregation somatic operation to be done with a fuzzy Gupta Integrator based on the Gupta fuzzy neurons theory [9]. The non-linear somatic operation with threshold is done through an activation function with a dynamical threshold. The threshold of the input signal to the activation function is a time-varying function. Therefore, the dynamic threshold of the activation function has a membership function that assigns membership values to the fuzzy integral of the non-fuzzy input signals to the fuzzy neuron. The response of the activation function is a time-varying fuzzy output signal with pulses of constant amplitude and variable duration and frequency according to the mapping done by the membership function threshold activation function. The fuzzy response of the activation function is the input signal for generating the spikes trains which are the fuzzy response of the fuzzy neuron model.

Figure 1 shows the general block diagram of the electronic circuit for generating spikes trains; these are the fuzzy responses of the fuzzy neuron. The input signals applied to the fuzzy neuron are $V_{\text {in } 1}(t)$ and $V_{\text {in2 }}(t)$. These analog input signals are then converted into input digital signals to the fuzzy neuron circuit where a fuzzy integral defined by Gupta [9] is applied as a generalized Max operator or generalized fuzzy OR, with $N$ inputs. Then the output signal of the fuzzy integrator enters into a step activation function as well as a triangular threshold signal $V_{\text {threshold }}(t)$ with a frequency of at least ten times the frequency of the input signals, this threshold signal is analog and is converted to digital.

Once the fuzzy neuron response $V_{\text {out }}(t)$ is obtained, a relative refractory period is applied to this signal and, afterwards, an axonal delay which can be selected between 0.1 to $1 \mathrm{~ms}$, later $V_{\text {out }}(t)$ enters to an AND gate with a clock signal $V_{\text {clk }}(t)$ used for the $A / D$ converters, the output signal $V_{\text {train }}(t)$ is clock pulses trains with constant amplitude but each pulse train in width and frequency is the result of the fuzzy integral of the fuzzy neuron input signals and the non-linear somatic operation with dynamic threshold.

The input signal $V_{\text {train }}(t)$ is then applied to the spiking generator circuit (SGC), as indicated in Figure 1, where finally spikes trains are obtained, all the spikes are of the same amplitude and of the same period of a clock pulse $\mathrm{V}_{\text {clk }}(\mathrm{t})$.

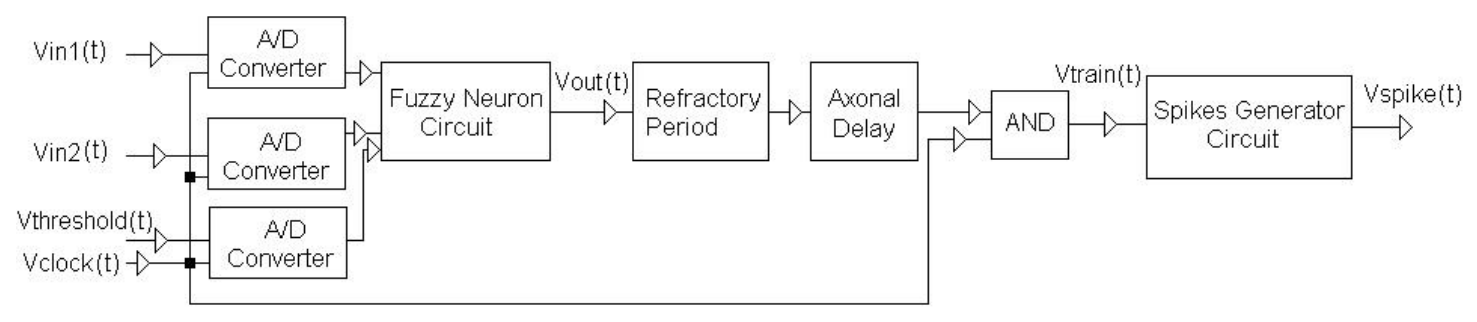

Figure 1. General block diagram of the electronic circuit for generating spikes trains similar to the fast spiking biological interneurons. 


\subsection{Fuzzy neuron model circuit}

The aggregation somatic operation for the fuzzy neuron model is defined as a Gupta fuzzy integrator (GFI) or generalized fuzzy OR of $N$ inputs formed by $\mathrm{N}-1$ fuzzy OR gates (Max operators) connected in cascade, to perform the somatic aggregation operation. The non-linear somatic operation with threshold is defined as an activation function (AF) with threshold and realizes the non-linear somatic operation with threshold which generates a fuzzy response of the fuzzy neuron.

The spiking fuzzy neuron with a Gupta fuzzy integrator developed in this paper is a fuzzy neuron with no fuzzy inputs [9]. The dendritic input signals $x_{i}(t)$ are classic voltage signals (non fuzzy) standardized from 0 to 5 Volts, defined inside the interval [ $\left[\begin{array}{ll}0 & 1\end{array}\right]$. The synaptic weights $w_{i}$ have an unit value, where $i=1,2,3, \ldots N$ and $N$ is the number of dendritic inputs to the fuzzy neuron.

For a fuzzy neuron with $N$ non-fuzzy inputs, the synaptic weight operations are replaced by membership functions. Then the result of each synaptic operation is the assignment of a membership value to each dendritic input signal corresponding to a fuzzy set, that is, the synaptic operation result is a fuzzy mapping $\widetilde{v}_{\text {ini }}(t)$. In this case, if the synaptic weights $w_{j ' s}(t)$ are considered with a unit value, thus the threshold for the activation function is replaced by a timevarying membership function of a dynamic threshold, then the result of the activation function is the assignment of a membership value to the fuzzy integral output signal corresponding to a fuzzy set, that is, the activation function result is a fuzzy mapping $\widetilde{v}_{\text {out }}(t)$.

The response $\widetilde{v}_{\text {out }}(t)$ is the somatic output signal of the non-linear somatic operation with threshold $\varphi[\mathrm{t}, \cdot]$ defined as a step activation function with a threshold signal $v_{\text {threshold }}(t)$ of the aggregation somatic operation of the synaptic operations of the dendritic input signals $\mathrm{X}_{\mathrm{j}^{\prime} \mathrm{s}}(\mathrm{t})$ and the synaptic weights $w_{j ' s}(t)$, which in this case are considered with a unit value, and $\widetilde{v}_{\text {out }}(t)$ is defined by Equation (1).

$$
\widetilde{\nabla}_{\text {out }}(t)=\left\{\begin{array}{l}
\operatorname{lif}\left(\begin{array}{c}
\mathrm{N} \\
\mathrm{j}=1
\end{array} \widetilde{\mathrm{v}}_{\text {inj }}(t)\right) \geq \mathrm{v}_{\text {threshold }}(t) \\
\operatorname{0if}\left(\begin{array}{c}
\mathrm{N} \\
\mathrm{M}=1
\end{array} \widetilde{\mathrm{v}}_{\text {inj }}(\mathrm{t})\right)<\mathrm{v}_{\text {threshold }}(t)
\end{array}\right\}=\widetilde{y}(\mathrm{t})
$$

Where $\widetilde{y}(t)$ is a fuzzy mapping of the Gupta fuzzy sum-integral $\widetilde{v}_{\text {max }}(t)$ of the dendritic input signals $x_{j ' s}(t)$ to the fuzzy neuron after performing the respective synaptic operations $\widetilde{v}_{\text {in's }}(t)$. The electronic digital circuit of the somatic operations of the proposed fuzzy neuron model is given in Figure 2.

\subsection{Refractory period circuit}

The refractory period is the time interval after a spike neuron emission in which the neuron does not respond to any input signal [24] and [25]. In the fuzzy neuron the refractory period is generated from the pulses of the output signal $V_{\text {out }}(t)$. The refractory period $T_{R}$ is implanted through an electronic circuit (Figure 3) which enables or disables the fuzzy neuron to respond to any input signal including the threshold input signal, that is, after a pulse in $V_{\text {out }}(t)$ is generated, a monostable multivibrator circuit is activated with the falling edge of the pulse $\left(t_{R i}\right)$ and generates in its output $\bar{Q}$ the control signal $V_{\text {ine }}(t)$, a low pulse.

If the electronic circuit of the fuzzy neuron is disabled $V_{\text {ine }}(t)=0$, it does not respond to any input signal, then $\vec{V}_{\text {in } 1} \cdot V_{\text {ine }}(t)=0, \quad \vec{V}_{\text {in2 }} \cdot V_{\text {ine }}(t)=0$ and $\vec{V}_{\text {threshold }}+\nabla_{\text {ine }}(t)=1$, therefore $V_{\text {out }}(t)=0$ during the refractory period $T_{R}$, where $\vec{V}_{\text {in1 }}=\left[V_{\text {in17 }}, V_{\text {in16 }}\right.$, $\left.V_{\text {in15 }}, V_{\text {in14 }}, V_{\text {in13 }}, V_{\text {in12 }}, V_{\text {in11 }}, V_{\text {in10 }}\right], \vec{V}_{\text {in2 }}=\left[V_{\text {in27 }}, V_{\text {in26 }}\right.$, $V_{\text {in25 }}, V_{\text {in24 }}, V_{\text {in23 }}, V_{\text {in22 }}, V_{\text {in21 }}, V_{\text {in20 }}$ and $\vec{V}_{\text {threshold }}=$ [ $\mathrm{V}_{\text {threshold7 }}, \mathrm{V}_{\text {threshold6, }}, \mathrm{V}_{\text {threshold5, }}, \mathrm{V}_{\text {threshold4, }}, \mathrm{V}_{\text {threshold3, }}$ $\mathrm{V}_{\text {threshold2}}, \mathrm{V}_{\text {threshold1 }}, \mathrm{V}_{\text {threshold0]. After this time interval }}$ $\left(T_{R}\right)$ the control signal $\mathrm{V}_{\text {ine }}(\mathrm{t})$ returns to the normally high state and the fuzzy neuron is enabled again. $T_{R}$ has a duration from 0 to $1 \mathrm{~ms}$ and is defined as $T_{R}=$ $0.7 \cdot R \cdot C$ 


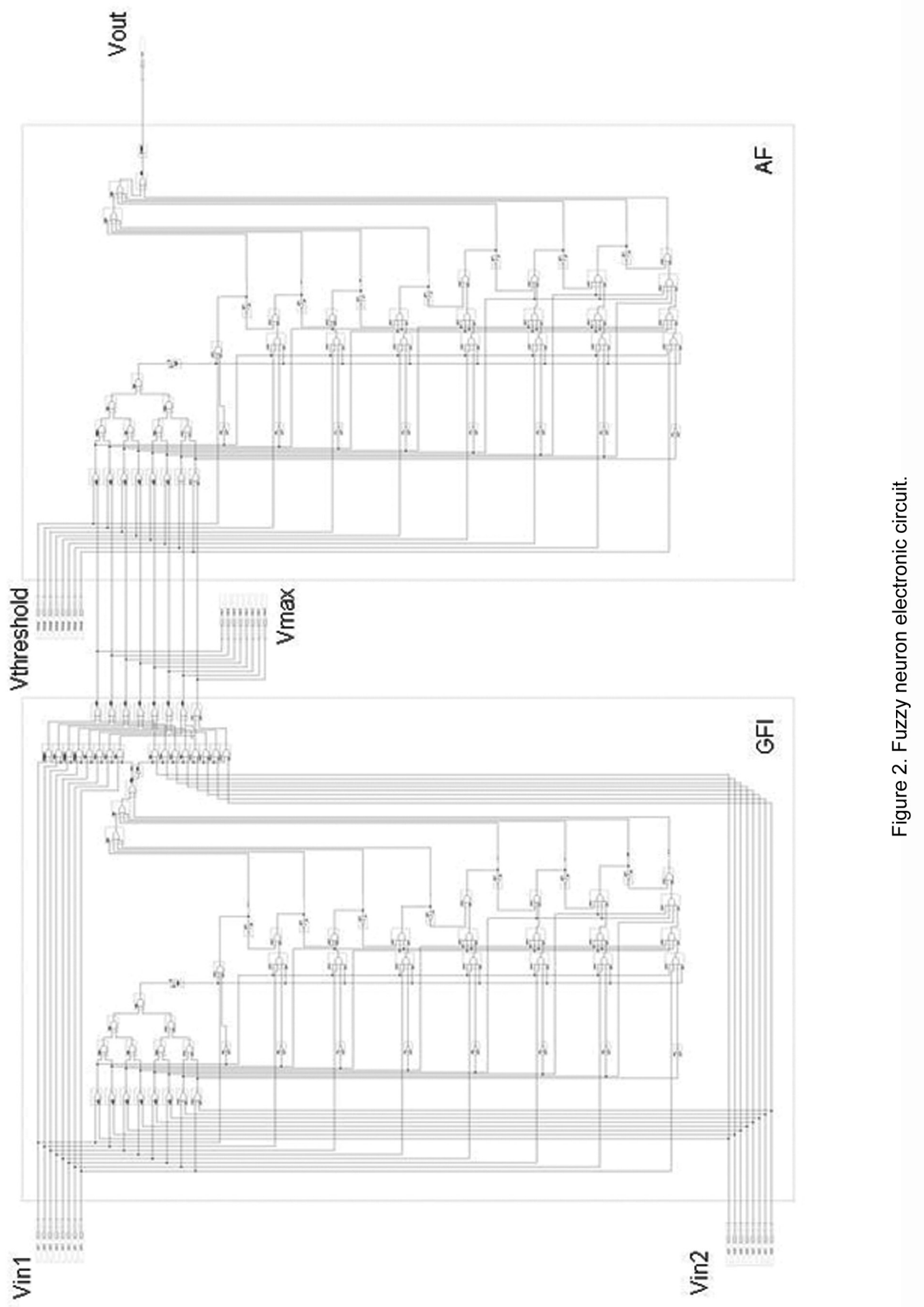




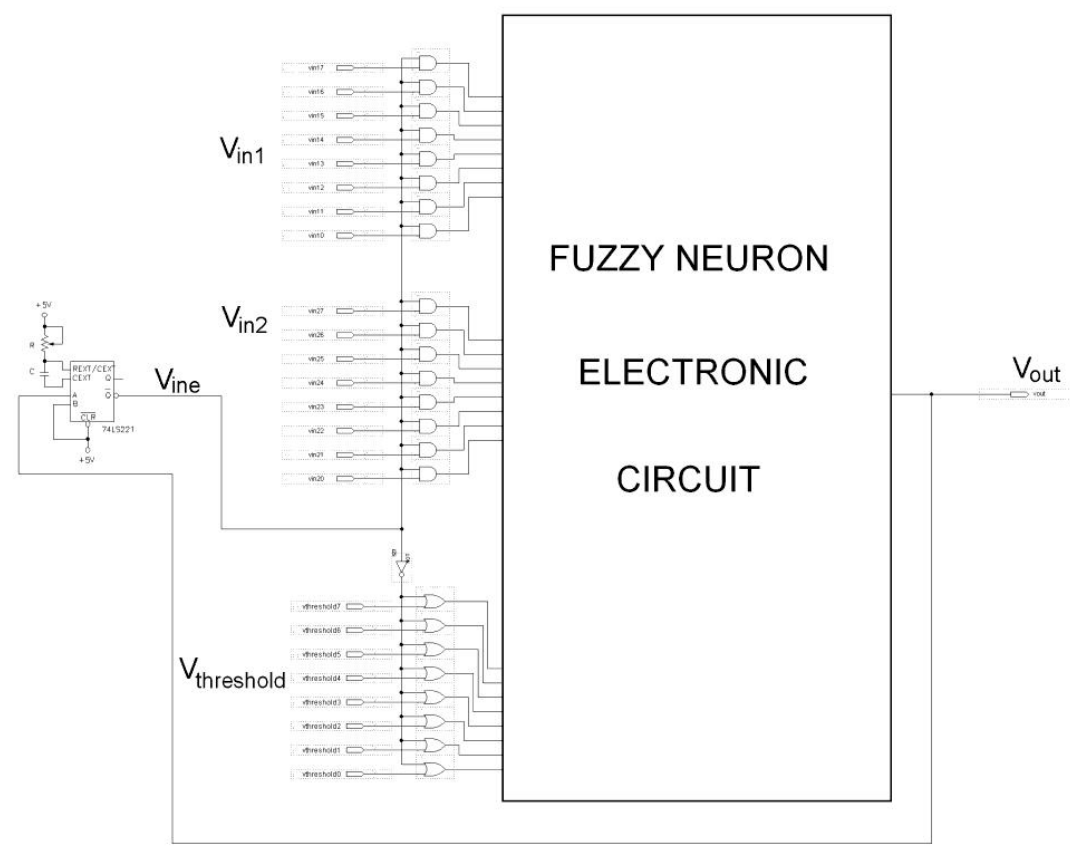

Figure 3. Electronic circuit to generate a refractory period to the response of the fuzzy neuron.

\subsection{Axonal delay circuit}

The axonal delay is the time in which the signal travels across the axon [25]. In order to produce an axonal delay to the fuzzy response $V_{\text {out }}(t)$ of the fuzzy neuron, shift registers with D flip-flops (Figure 4) were used connected in cascade. If the initial time is $t_{0}=0 \mathrm{~s}$ and the delay applied to $\mathrm{V}_{\text {out }}(\mathrm{t})$ in each flipflop is a 2 clock cycle, then for a clock frequency $f_{c l k}$ $=500 \mathrm{KHz}$ of the signal clock $\mathrm{V}_{\text {clock }}(\mathrm{t})$, two clock cycles $=4 \mu \mathrm{s}$ and therefore we have 10 axonal delays $t_{A D 1}, t_{A D 2}, \ldots t_{A D 10}$, available every $100 \mu \mathrm{s}$.

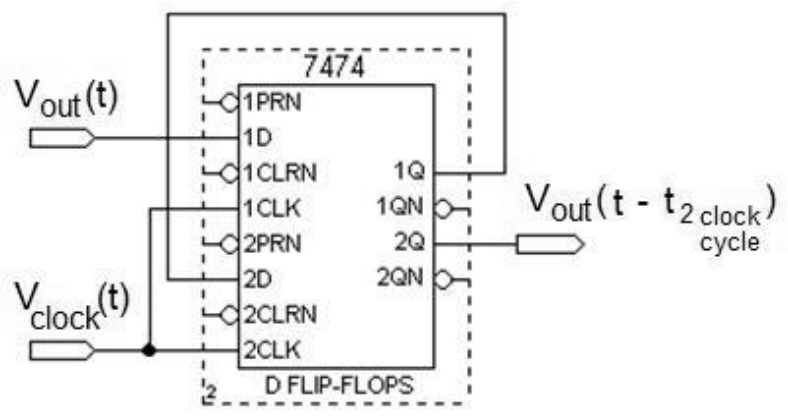

Figure 4. Axonal delay electronic circuit.

\subsection{Spike-generator circuit}

The spike-generator electronic circuit was developed from the fuzzy neuron response $V_{\text {out }}(t)$, Figure 1 . Based on the general block diagram in Figure 1 in order to obtain spikes, a logic AND gate is required and a spike-generator electronic circuit. For the signal $V_{\text {train }}(t)$ we have Equations (2) and (3) :

$$
\begin{aligned}
& V_{\text {train }}(t)=V_{\text {out }}(t) \cdot V_{\text {clock }}(t) \\
& V_{\text {train }}(t)=V_{\text {out }}(t) \text { AND } V_{\text {clock }}(t)
\end{aligned}
$$

For the next stage in the spike-generator circuit (SGC), we propose an electronic circuit which converts the input signal $V_{\text {train }}(t)$ into a bipolar square signal with an amplitude of $+V$ to $-V$. Because the spikes are bipolar signals, that is, with a positive and negative part, therefore we have Equation (4):

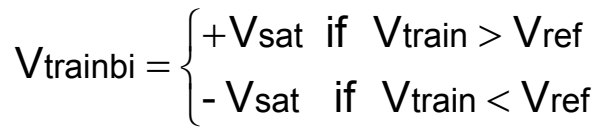


where:

$+\mathrm{V}_{\text {sat }}=+\mathrm{V}$ (positive saturation voltage)

$-V_{\text {sat }}=-V$ (negative saturation voltage)

Based on the bipolar signal $\mathrm{V}_{\text {trainbi }}(\mathrm{t})$, the spikes are obtained according to the SGC in Figure 5 which is defined by Equation (5):

\section{Results}

The fuzzy neuron electronic circuit as well as the axonal delay electronic circuit are implanted in Altera ${ }^{\circledR}$ microcircuits, PLDs (programmable logic devices), of the Max 7000S EPM7128SLC84 family [26]. A printed circuit of the fuzzy neuron electronic circuit with refractory period, axonal delay and the spike-generator has been implemented including a 5 $V_{D C}$ voltage regulator, three 8 bits A/D ADC0801 for the analog input signals of the fuzzy neuron. The printed circuit board was manufactured in the
Laboratory of Electronics at Centro de Ciencias Aplicadas y Desarrollo Tecnológico of the Universidad Nacional Autónoma de México.

In order to prove the fuzzy neuron model proposed in this paper, two analog sinusoidal signals $V_{\text {in } 1}(t)$ and $V_{\text {in2 }}(t)$ with a frequency of $1 \mathrm{KHz}, 5 \mathrm{Vpp}$ of amplitude and $180^{\circ}$ out of phase from one another, as shown in Figure 6, were applied. Figure 7 illustrates the threshold triangular input signal $V_{\text {threshold }}(t)$ with a frequency of $10 \mathrm{KHz}$ and $5 \mathrm{Vpp}$ of amplitude. The clock signals $V_{\text {clk }}(t)$ are square pulses with a frequency of $500 \mathrm{KHz}$ and $5 \mathrm{Vpp}$ of amplitude. The output of the fuzzy neuron $V_{\text {out }}(t)$ is constituted by square pulses with constant amplitude, the pulse width and frequency are result of the fuzzy integral of the input signals $V_{\text {in1 } 1}(t)$ and $V_{\text {in } 2}(t)$, that is, $V_{\text {out }}(t)$ is the maximum of the amplitude of the two input signals after the non linear somatic operation with threshold or activation function, Figure 7 , channel 3.

$$
\left[V_{\text {spike }}(t)=E_{\text {out }}=R_{3} l_{s}\left(e^{\frac{K V_{D}(t)}{T_{k}}}-1\right)-\frac{R_{3}}{R_{1}} V_{\text {trainbi }}(t)-\left(\frac{R_{2}}{R_{1}}+1\right) R_{3} C_{1} \frac{d V_{\text {trainbi }}(t)}{d t}\right]
$$

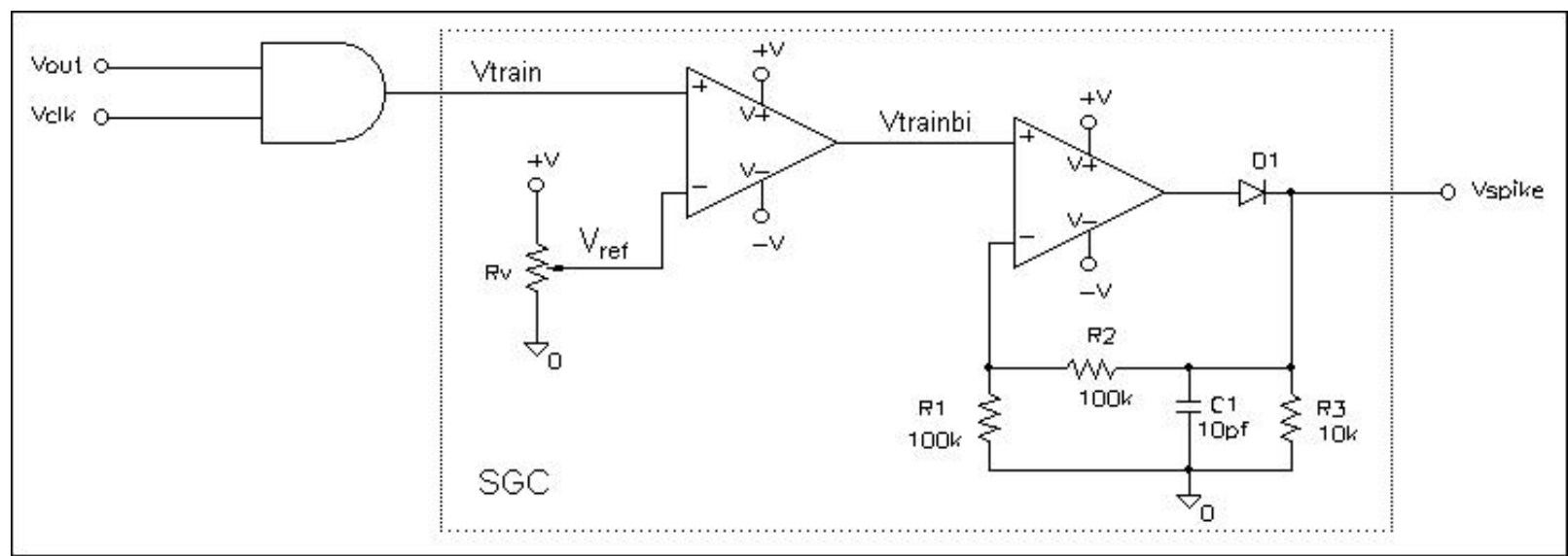

Figure 5. Spike-generator electronic circuit. 


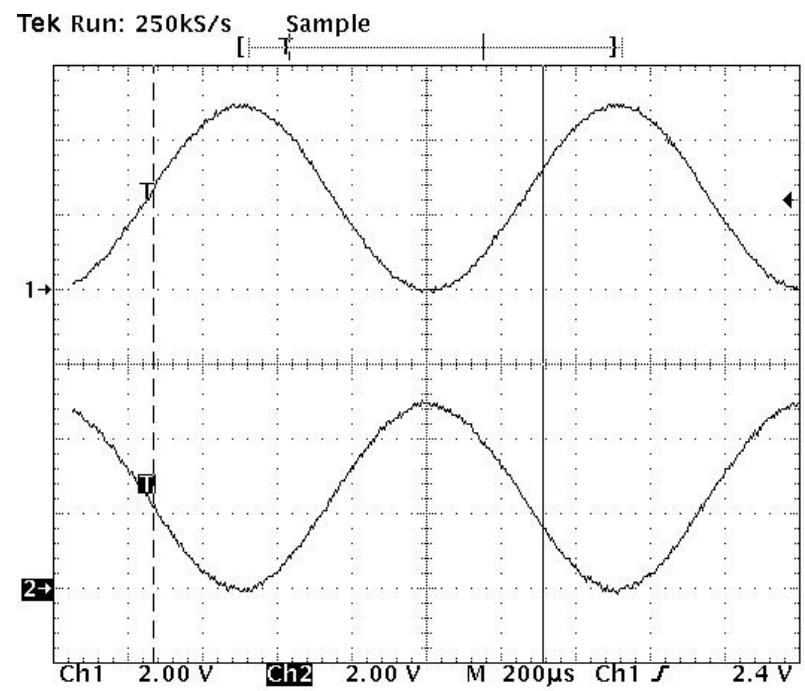

Figure 6. (1) Fuzzy neuron analog input signal $V_{\text {in1 }}(t)$. (2) Fuzzy neuron analog input signal $\mathrm{V}_{\text {in2 }}(\mathrm{t})$.

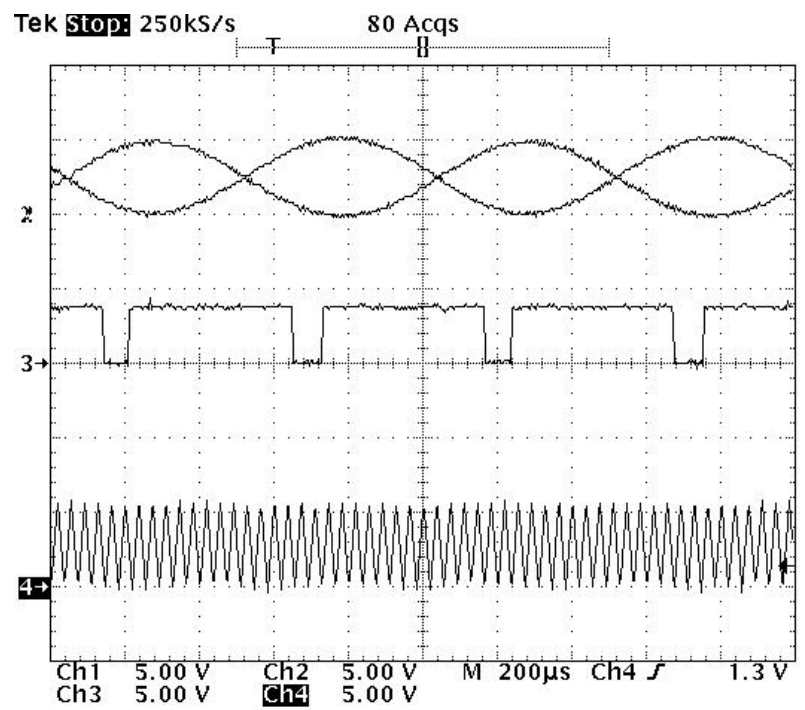

Figure 7. (1) Fuzzy neuron analog input signal $V_{\text {in } 1}(t),(2)$ Fuzzy neuron analog input signal $V_{\text {in2 }}(t)$, (3) Fuzzy neuron digital output signal $\mathrm{V}_{\text {out }}(\mathrm{t})$ and $(4)$ Fuzzy neuron threshold analog input signal $\mathrm{V}_{\text {threshold }}(\mathrm{t})$.

The refractory period $T_{R}$ where the fuzzy neuron is unresponsive to any input excitation signal, after a pulse in $V_{\text {out }}(t)$ is generated, is observed in the oscillograms of Figures 8 and 9 . The fuzzy response of the fuzzy neuron model $\mathrm{V}_{\text {out }}(\mathrm{t})$ without refractory period is presented in Figure 8 , and the output signal $\mathrm{V}_{\text {out }}(\mathrm{t})$ with the effect of the refractory period $T_{R}$ of approximately $0.4 \mathrm{~ms}$ is illustrated in Figure 9.

The axonal delay effect on the fuzzy response $V_{\text {out }}(t)$ of the fuzzy neuron could be observed in channels 1 , 2, 3 and 4 in the oscillogram in Figure 10 with different axonal delays $\mathrm{V}_{\text {out1 } 1}(\mathrm{t}), \mathrm{V}_{\text {out2 }}(\mathrm{t})$ and $\mathrm{V}_{\text {out } 3}(\mathrm{t})$ which are shown simultaneously; in channel 1 the output signal $V_{\text {out }}(t)$ is shown without any axonal delay $\left(\mathrm{t}_{0}\right)$, in channel $2 \mathrm{~V}_{\text {out } 1}(\mathrm{t})$ has an axonal delay $\left(t_{0}\right.$ $\left.-t_{A D 1}\right)$ of $0.1 \mathrm{~ms}$ with respect to $V_{\text {out }}(t)$, in channel 3 $\mathrm{V}_{\text {out2 }}(\mathrm{t})$ has an axonal delay $\left(t_{0}-t_{A D 2}\right)$ of $0.2 \mathrm{~ms}$ with respect to $V_{\text {out }}(t)$ and in channel $4 V_{\text {out } 3}(t)$ has an axonal delay $\left(t_{0}-t_{A D 3}\right)$ of $0.3 \mathrm{~ms}$ with respect to $\mathrm{V}_{\text {out }}(\mathrm{t})$.

Although there are ten output signals parallel $V_{\text {out } 1}(t)$, $\mathrm{V}_{\text {out2 }}(\mathrm{t}) \ldots \mathrm{V}_{\text {out10 }}(\mathrm{t})$ with axonal delay of 0.1 to $1 \mathrm{~ms}$, only one of these output signals $V_{\text {out }}(t)$ could be the input signal to the spike-generator circuit in order to obtain $V_{\text {spike }}(t)$ spike trains consisting of action potentials of the same shape and duration each.

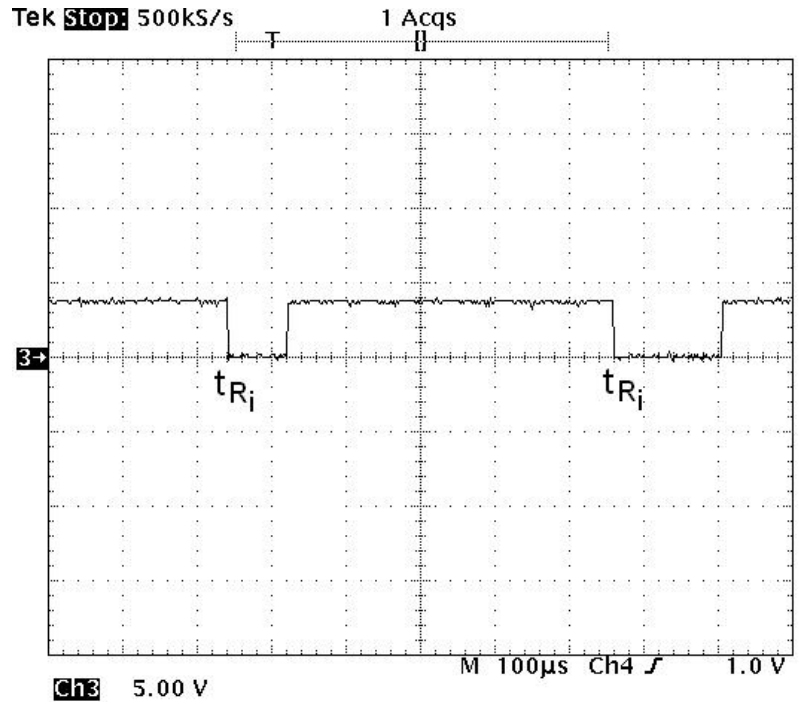

Figure 8. (3) Activation function output signal Vout(t) without refractory period. 


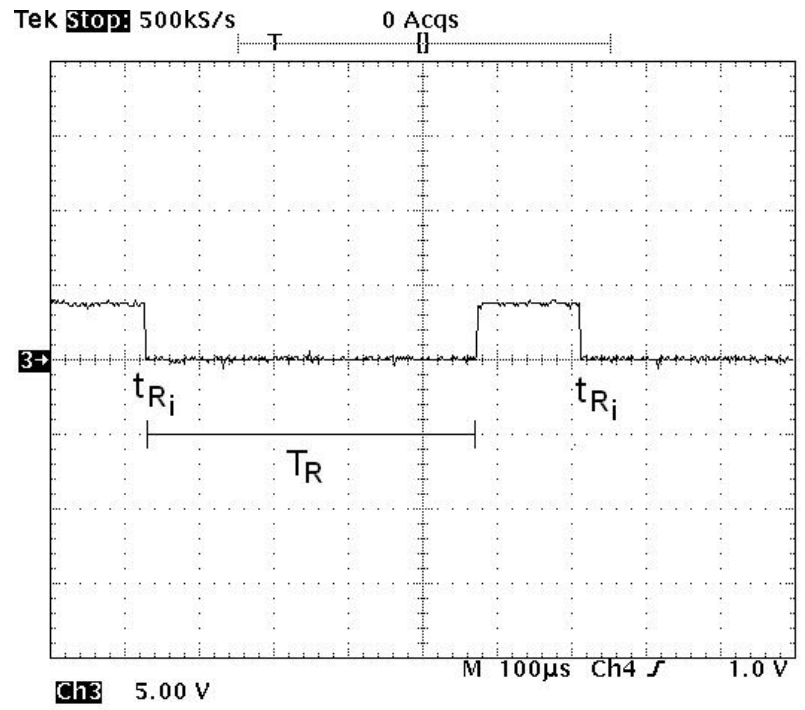

Figure 9. (3) Activation function output signal $\mathrm{V}_{\text {out }}(\mathrm{t})$ with a refractory period $T_{R}$.

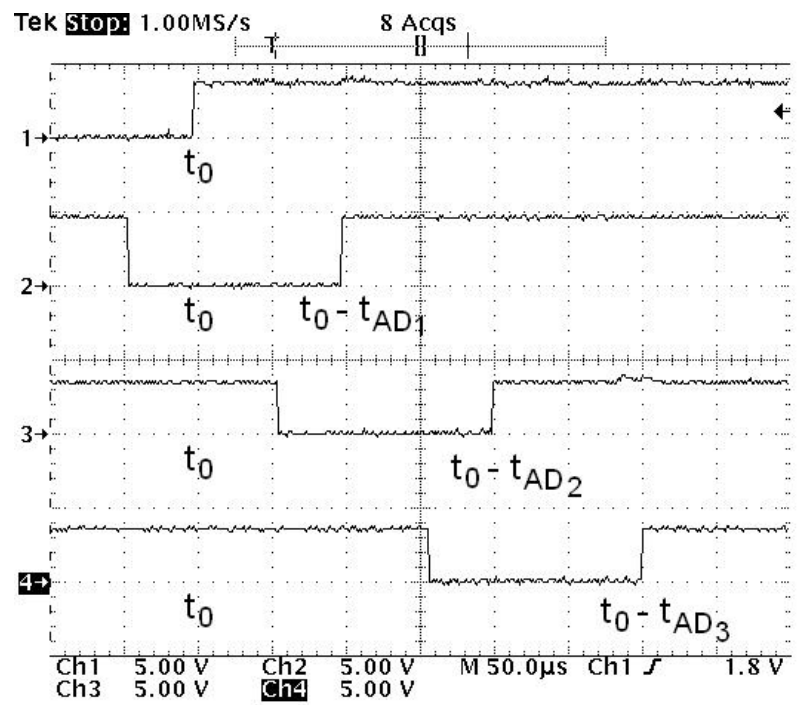

Figure 10. (1) Activation function output signal $\mathrm{V}_{\text {out }}(\mathrm{t})$ without axonal delay, (2) Activation function output signal $\mathrm{V}_{\text {out } 1}(\mathrm{t})$ with axonal delay of $0.1 \mathrm{~ms}$, (3) Activation function output signal $\mathrm{V}_{\text {out2 }}(\mathrm{t})$ with axonal delay of 0.2 $\mathrm{ms},(4)$ Activation function output signal $\mathrm{V}_{\text {out } 3}(\mathrm{t})$ with axonal delay of $0.3 \mathrm{~ms}$.

With the purpose of simulating the performance and response of a fast-spiking biological neuron and based on the output signal $\mathrm{V}_{\text {out }}(\mathrm{t})$ (Figure 8), the signal $V_{\text {train }}(t)$, consisting of trains of clock pulses, was obtained, later the signal $\mathrm{V}_{\text {trainbi }}(\mathrm{t})$, consisting of trains of bipolar clock pulses, and finally, the output signal $\mathrm{V}_{\text {spike }}(\mathrm{t})$, consisting of spike trains as shown in channel 3 in Figure 11. The duration and frequency of these spike trains or action potentials of the same shape and period constitute the response of the fuzzy neuron model.

The comparison of the initial transient envelope train of spikes of the fuzzy response in Figure 12 obtained from the fuzzy neuron model proposed in this paper, with the register obtained from a biological cortical neuron [10], confirms the biological similarity between the two responses.

Figure 11 shows the spikes of the fuzzy response $V_{\text {spike }}(t)$, the shape and length in each spike is the same, therefore, the length and frequency of the spike trains provides the information in the input signals $V_{\text {in } 1}(t)$ and $V_{\text {in2 }}(t)$ after a fuzzy process like the Gupta fuzzy integral and the step activation function with dynamic threshold, besides the refractory period and the axonal delay of the fuzzy neuron model. The duration and frequency of the spike trains are the result of the fuzzy integral of the fuzzy neuron input signals.

Also observed in Figure 11, a spike period is $2 \mu \mathrm{s}$, a period of a signal clock $V_{\text {clk }}(t)$, and the minimum distance between two spikes is defined as the absolute refractory period of the spikes, this constant period between each spike is $1 \mu \mathrm{s}$ considering the signal clock $\mathrm{V}_{\text {clk }}(\mathrm{t})$ frequency of $500 \mathrm{KHz}$.

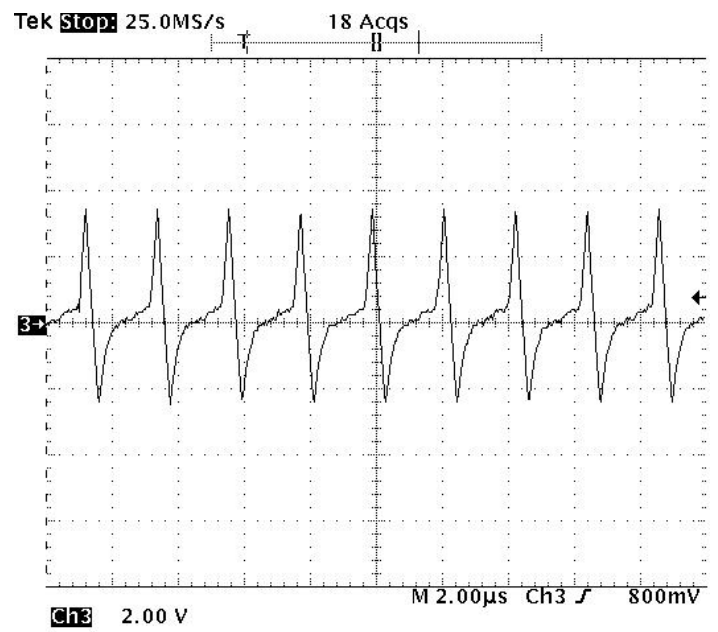

Figure 11. (3) Spikes of the fuzzy neuron response Vspike(t). 
The fuzzy neuron response with an axonal delay applied $\left(t_{0}-t_{A D 1}\right)$ is shown in Figure 12. It is observed that the spike shape is preserved even after the axonal delay. Thus, this demonstrates the initial hypothesis of making digitally the axonal delay and before the spike generation, and then the information in the spike trains is also preserved according to the objective set at the beginning of this paper.

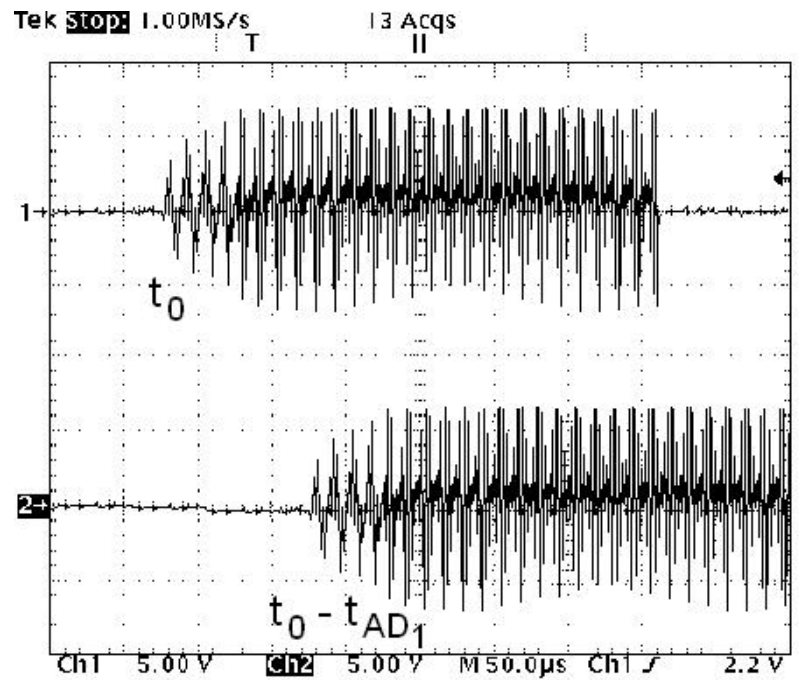

Figure 12. (1) Spike train of the fuzzy neuron response Vspike(t). (2) Spike train of the fuzzy neuron response Vspike(t) with axonal delay.
Also in terms of the spike shape and distribution (absolute refractory period) of the fuzzy response of the fuzzy neuron model proposed (Figure 11), the behavior corresponds to the fast spiking cortical interneurons according to records shown in [18].

3.1 Comparison of the results of the fuzzy neuron model electronic circuit with the simulation results of the mathematical fuzzy neuron model in Matlabß.

In order to compare the results obtained from the fuzzy neuron electronic circuit, a simulation of the mathematical fuzzy neuron model was made in Matlab $\otimes$. Figure 13 shows the input signals $V_{\text {in } 1}(t)$ and $V_{\text {in2 }}(t)$, the fuzzy integral $V_{\max }(t)$, the threshold signal for the activation function $V_{\text {threshold }}(t)$, and the activation function output signal $\mathrm{V}_{\text {out }}(\mathrm{t})$. Figure 14 shows the output signal $\mathrm{V}_{\text {out }}(\mathrm{t})$ with a refractory period $T_{R}=0.1$ $\mathrm{ms}$ where the fuzzy neuron is unresponsive to any excitation signal after a pulse in $V_{\text {out }}(t)$ is generated.

The digital output signal $\mathrm{V}_{\text {out }}(\mathrm{t})$ with four different axonal delays $V_{\text {out } 1}(t)$ with $0.1 \mathrm{~ms}$, $\mathrm{V}_{\text {out } 2}(\mathrm{t})$ with $0.2 \mathrm{~ms}$ and $\mathrm{V}_{\text {out } 3}(\mathrm{t})$ with $0.3 \mathrm{~ms}$ are shown in Figure 15.

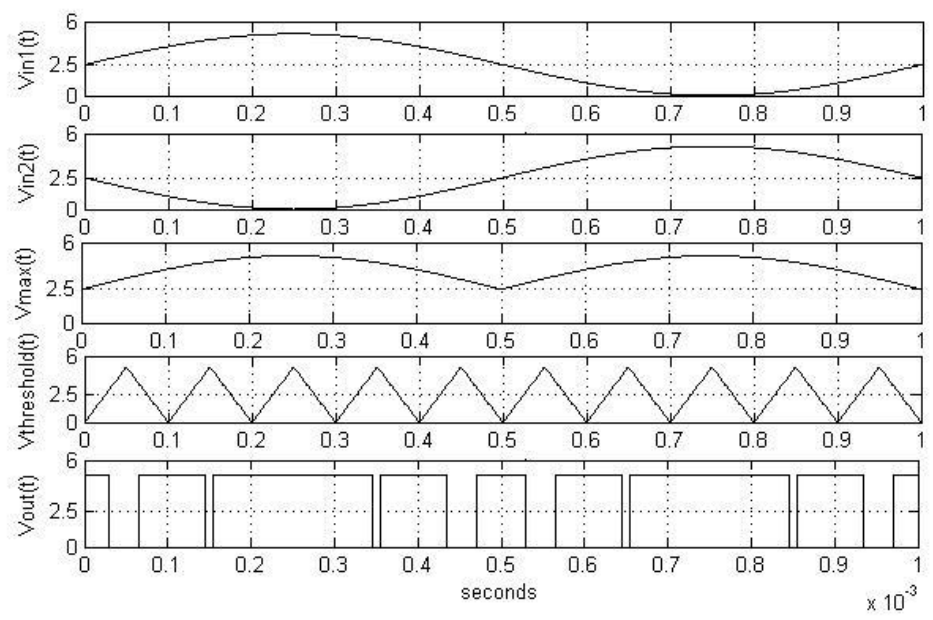

Figure 13. $V_{\text {in } 1}(t)$ fuzzy neuron analog input signal, $V_{\text {in2 }}(t)$ fuzzy neuron analog input signal, $V_{\max }(t)$ fuzzy integral of the fuzzy neuron input signals, $V_{\text {threshold }}(t)$ fuzzy neuron threshold analog input signal and $V_{\text {out }}(t)$ activation function digital output signal. 

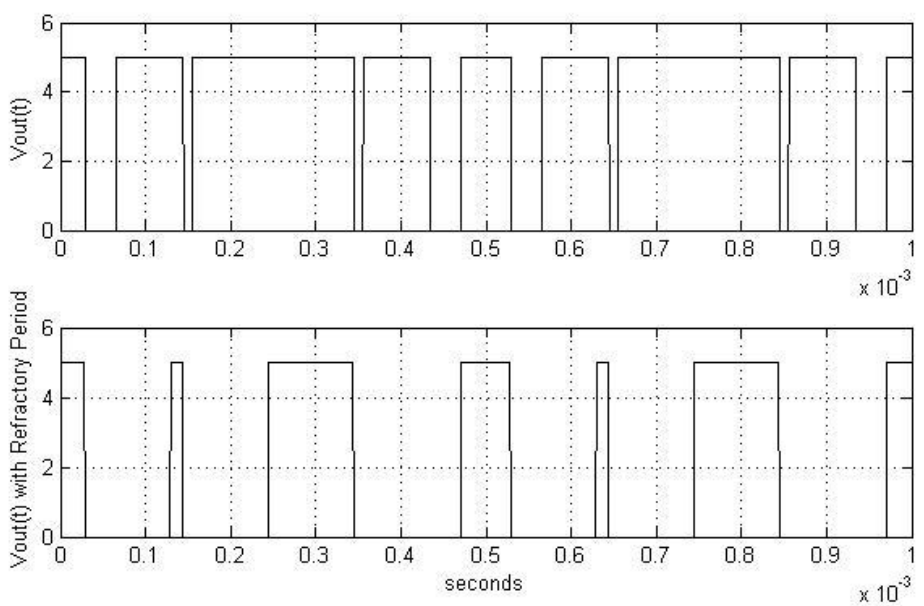

Figure 14. Vout(t) activation function digital output signal and Vout(t) activation function digital output signal with refractory period of $0.1 \mathrm{~ms}$.
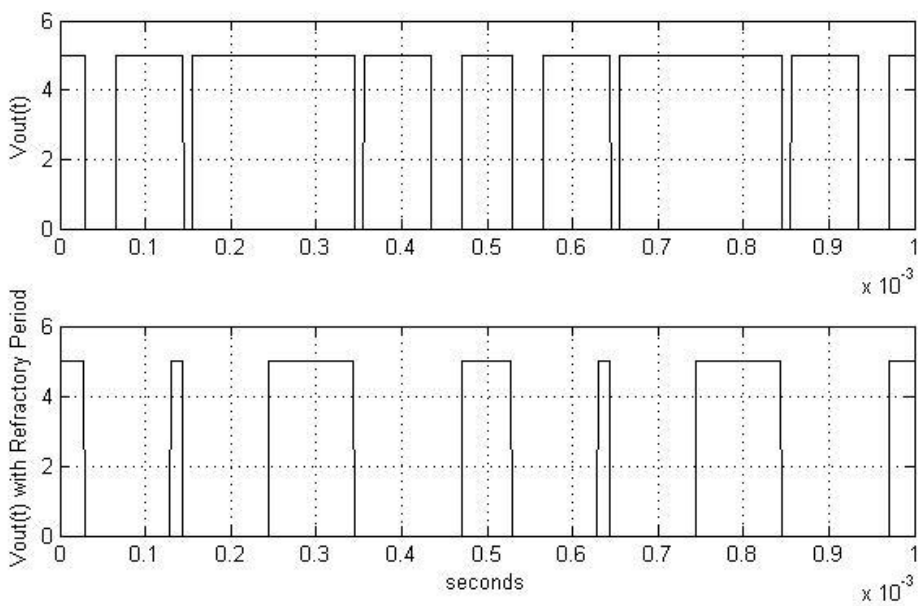

Figure 15. $\mathrm{V}_{\text {out }}(\mathrm{t})$ activation function output signal without axonal delay, $\mathrm{V}_{\text {out1 }}(\mathrm{t})$ activation function output signal with axonal delay of $0.1 \mathrm{~ms}, \mathrm{~V}_{\text {out2 }}(\mathrm{t})$ activation function output signal with axonal delay of $0.2 \mathrm{~ms}$ and $\mathrm{V}_{\text {out } 3}(\mathrm{t})$ activation function output signal with axonal delay of $0.3 \mathrm{~ms}$.

Figure 16 shows the spikes of the spike trains of the fuzzy neuron response, the spike period is $2 \mu \mathrm{s}$, and the absolute refractory period is $1 \mu \mathrm{s}$. The fuzzy neuron response $V_{\text {spike }}(t)$ and the fuzzy neuron response with axonal delay of $0.1 \mathrm{~ms} \mathrm{~V}_{\text {spike }}\left(t-t_{A D 1}\right)$ are shown in Figure 17. Comparing Figures 11 and 12 , the spike shape is preserved even after the axonal delay process in both figures and a difference between Figures 16 and 17 is the transient presented at the beginning of each spike train. In Figure 16, the transient observed is similar to the response of biological spiking neurons [10] and [18]. The same response could be obtained from a microcontroller, however, the mathematical model would be more complex and a great amount of memory would be required compared with the digital circuits used in this fuzzy neuron model. 


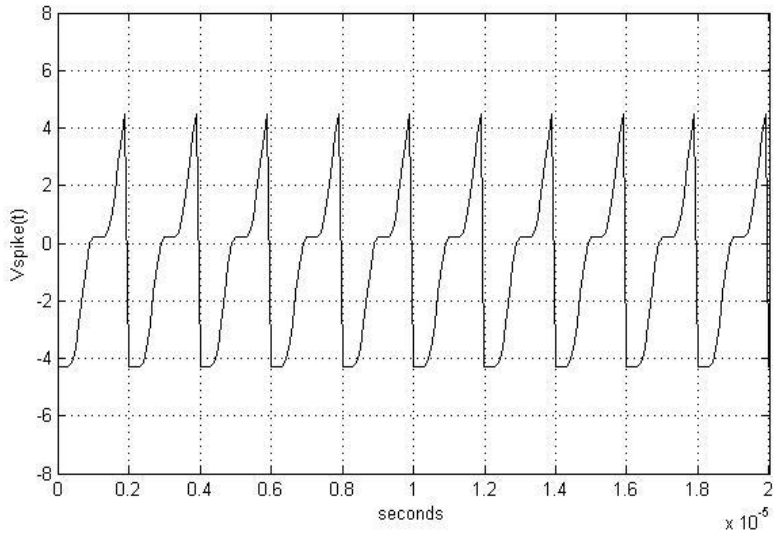

Figure 16. $V_{\text {spike }}(t)$ Spikes of the fuzzy neuron response.

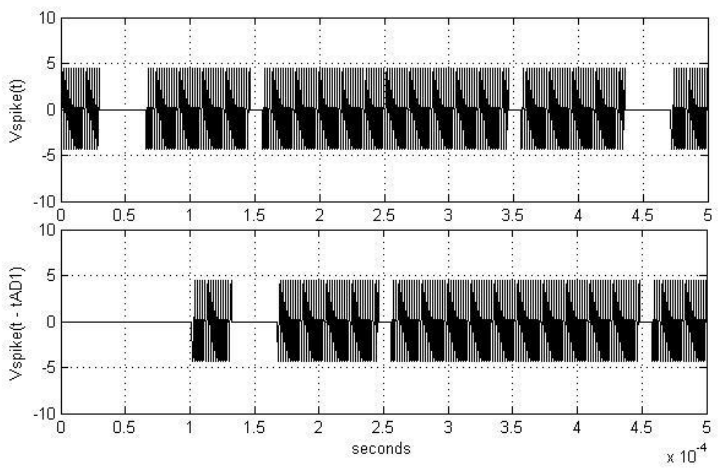

Figure 17. $V_{\text {spike }}(t)$ Spike trains of the fuzzy neuron response and $V_{\text {spike }}\left(t-t_{A D 1}\right)$ spike trains of the fuzzy neuron response with axonal delay of $0.1 \mathrm{~ms}$.

\section{Conclusions}

A fuzzy neuron model is developed for the synaptic and somatic aggregation operations, the non-linear step activation function with threshold, and the neural features such as the refractory period and the axonal delay. The equations for the spike traingenerator were also given. The mathematical model equations and the electronic circuit equations for the fuzzy neuron model both describe the fuzzy neural processes from the classic analog input signals to the fuzzy neuron response.

Comparing the fuzzy neuron model given in this paper with others fuzzy and non-fuzzy neuron models which include some of the neural features like the refractory period and the axonal delay, one of the advantages of the fuzzy neuron model is that the shape and length of the spike trains of the fuzzy response are preserved even after the effect of the refractory period and the axonal delay, because the neural somatic processes in the fuzzy neuron are performed in a digital way and before the spike generation with analog electronic circuits, preserving in this form not only the frequency and length of the spike trains but also the spike shape and the absolute refractory period in the fuzzy neuron response.

The contributions in this paper are a consequence of the work reported in [7] and [21]. These contributions are the mathematical and electronic models of the fuzzy neuron, the neural features like the refractory period, the axonal delay and the spiking generation. Also a printed circuit of the fuzzy neuron model was implemented and tested for two classic analog input signals with a fuzzy neuron response as result.

Another advantage of this fuzzy neuron model is that the neuronal processes like the refractory period and axonal delay are made in a digital form before the spiking generation. There are also ten digital axonal delays available in parallel for the output signal $\mathrm{V}_{\text {out }}(\mathrm{t})$.

By comparing the fuzzy response of the fuzzy neuron model with registers and results presented in other studies [10] and [18] about fast spiking biological cortical neurons and interneurons, similarities were found in the electrical response in terms of shape, frequency and distribution of the spike trains obtained in the fuzzy neuron model developed in this work and confirming the hypothesis presented at the beginning in this paper. 


\section{References}

[1] A. N. Burkitt, "A review of the integrate-and-fire neuron model: I. Homogeneous synaptic input", Biological Cybernetics, Vol. 95, 2006, pp. 1-19.

[2] Teresa B. Ludermir and Wilson R. de Oliveira, "Weightless Neural Models", Computer Standards \& Interfaces 16, 1994, pp. 253-263.

[3] Chaturvedi D.K., Satsangi P.S. and Prem K. Kalra, "New Neuron Models for Simulating Rotating Electrical Machines and load forecasting problems", Electric Power Systems Research 52, 1999, pp.123-131.

[4] Pérez S. J.L., Herrera A., et al, "Electronics Implementation of a Neuron Model with parabolic burst response", Third International Workshop on Design of Mixed-Mode Integrated Circuits and Applications, 26-28 July 1999, pp. 122-125.

[5] Pérez S. J. L., Garces A., et al, "Electronic Model of a Neuronal Sinapsis of Voltage to Frequency, and Frequency to Voltage conversion", Third International Workshop on Design of Mixed-Mode Integrated Circuits and Applications, 26-28 July 1999, pp.171-174.

[6] Ramírez Mendoza Abigaíl M. E., "Modelado Electrónico de dos Neuronas Integradoras Borrosas", Tesis de Maestría, División de Estudios de Posgrado de la Facultad de Ingeniería de la U.N.A.M., México, 1998.

[7] Pérez J. L., Ramírez A., "Two New Models of Integrative Fuzzy Neuron", Instrumentation \& Development, Vol. 5, Nr.3, Diciembre, 2001, pp. 140-145.

[8] Pérez S. J. L., Lara-Rosano F., Herrera, A. et al, "Electronic Model of a Extended Fuzzy Neuron", Proceedings of The Second Join México - E.U.A. International Conference on Neural Networks and Neurocontrol (Sian Ka'an 97), Playa del Carmen, México, Agosto 19-29, 1997, pp. 189-199.

[9] Gupta M.M. and Qi J., "On Fuzzy Neuron Models", Fuzzy logic for the management of uncertainty, Ed. Lotfi A. Zadeh and Janusz Kacprzyk, ISBN: 0-471-54799-9, 1992, pp. 479-491.

[10] N. D. Velasco, R. Ávila-Pozos, F. R. Godínez, "Desarrollo de un software de estimulación y adquisición de señales eléctricas celulares, basado en una tarjeta comercial de adquisición de datos", Revista mexicana de ingeniería biomédica Vol. XXVI, No. 2, Septiembre, 2005, pp. 92-105.
[11] Nicolas Langlois, Pierre Miché, Abdelaziz Bensrhair, "Analogue circuits of a learning spiking neuron model", IEEE, 2000, pp. 485-489.

[12] Jayawa H. B. Wijekoon and Piotr Dudek, "Integrated circuit implementation of a cortical neuron", IEEE, 2008, pp. 1784-1787.

[13] Eugene M. Izhikevich, "Simple Model of Spiking Neurons", IEEE Transactions on neural networks, Vol. 14, No. 6, November, 2003, pp. 1569-1572.

[14] Witold Pedrycz, Marek Reformat, and Kuwen Li, "OR/AND Neurons and the development of interpretable logic models", IEEE Transactions on neural networks, Vol. 17, No. 3, May, 2006, pp. 636-658.

[15] Gerstner Wulfram, Werner Kistler, "Spiking Neuron Models", Ed. Cambridge University Press, 2002, pp. 1-10, 93-94.

[16] J.L. Pérez S., A. Garcés M., F. Cabiedes C., A. Miranda V., "Electronic model of a dubois fuzzy integration neuron", Journal of Applied Research and Technology, Vol.7 No. 1 April 2009, pp. 73-82.

[17] M. Sekerli, R. J. Butera, "An Implementation of a Simple Neuron Model in Field Programmable Analog Arrays", Proceedings of the 26th Annual International Conference of the IEEE EMBS, San Francisco, CA, USA, September 1-5, 2004, pp. 4564-4567.

[18] David Golomb, Karnit Donner, Liron Shacham, Dan Shlosberg, Yael Amitai, David Hansel, "Mechanisms of Firing Patterns in Fast-Spiking Cortical Interneurons", PLoS Computational Biology, Vol. 3 No. 8, agosto 2007, pp. 1498-1512.

[19] Evyatar Av-Ron, Hanna Parnas, Lee A. Segel, "A basic biophysical model for bursting neurons", Biological Cybernetics, Springer-Verlag, 1993, Vol. 69, pp. 87-95.

[20] M. Scholles, B.J. Hosticka, M. Kesper, P. Richert, and M. Schwarz, "Biologically-Inspired Artificial Neurons: Modeling and Applications", Proceedings of 1993 International Joint Conference on Neural Networks, 1993, pp. 2300-2303.

[21] Ramírez A., Pérez J. L., "A Fuzzy Gupta Integrator Neuron Model with Spikes Response and Axonal delay", in Advances in Artificial Intelligence \& Engineering Cybernetics, Vol. IX George E. Lasker (Ed.), Windsor, Canada: IIAS, ISBN: 1894613449, 2002, pp.12 - 16.

[22] Lazzaro J., "Low Power Silicon Spiking Neurons and Axons", Circuits and Systems, ISCAS'92 Proceedings, IEEE International Symposium, Vol. 5, San Diego, CA, USA, 10-13 May 1992, pp. 2220-2223. 
[23] Inawashiro S., Miyake S., Ito M., "Spiking Neuron Models for Regular-Spiking, Intrinsically Bursting, and

Fast-Spiking Neurons", Proceedings 6th International Conference on Neural Information Processing, Vol. 1, 1620 November 1999, pp. 32-36.

[24] Daniel J. Amit, Modeling Brain Function, Cambridge University Press, New York, United States of America, 1989, pp. 12-17, 375-377.

[25] Gordon M. Shepherd, "Neurobiology", Oxford University Press, New York, United States of America, 1994, pp. 54, 88-89.

[26] www.altera.com 


\section{Authors' Biographies}

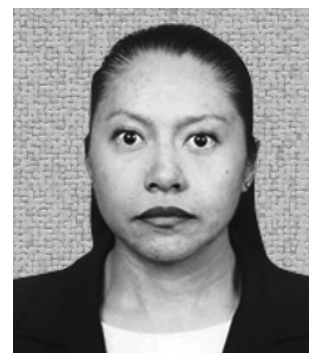

\section{Abigail María Elena RAMÍREZ-MENDOZA}

She received her BS in mechanical and electrical engineering (electrical and electronics area) from the Facultad de Ingeniería of the Universidad Nacional Autónoma de México, UNAM, in 1996. In 1998, she earned her master's degree in electrical engineering (electronics option) from UNAM (División de Estudios de Posgrado, Facultad de Ingeniería).

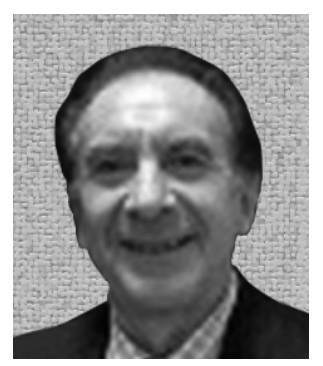

\section{Felipe de Jesús LARA-ROSANO}

$\mathrm{He}$ is a ' $\mathrm{C}$ ' senior researcher at Centro de Ciencias Aplicadas y Desarrollo Tecnológico of Universidad Nacional Autónoma de México. The contributions of Dr. Lara-Rosano as a researcher have been in three main areas: modeling of complex systems, specifically interconnected systems and networks, b) computerized decision support, and c) artificial intelligence computer systems, especially expert systems. His contributions have appeared in 106 international peer-reviewed publications, 86 national peer-reviewed publications and 34 national technology development products. He is a member of the National System of Researchers since its founding in 1984, where he currently holds level 3, the Mexican Academy of Sciences, the Academy of Engineering, the New York Academy of Sciences, the IEEE and the International Institute for advanced Research and Cybernetics Systems which awarded him the Doctorate Honoris Causa. 